\title{
First simulations of day-to-day variability of mid-latitude sporadic E layer structures
}

\author{
Satoshi Andoh ${ }^{1 *}$, Akinori Saito ${ }^{1}$, Hiroyuki Shinagawa ${ }^{2}$ and Mitsumu K. Ejiri $3{ }^{3,4}$
}

\begin{abstract}
We present the first simulations that successfully reproduce the day-to-day variability of the mid-latitude sporadic $\mathrm{E}\left(E_{s}\right)$ layers. $E_{s}$ layers appearing in the lower ionosphere have been extensively investigated to monitor and forecast their effects on long-distance communication by radio waves. Although it is widely accepted that the atmospheric tides are important in generating the $E_{s}$ layers, no simulations to date have reproduced the $E_{s}$ layers observed on a certain day. This is due to the lack of the combination of realistic information on the atmospheric tides in the lower ionosphere and a three-dimensional numerical ionospheric model that can simulate the precise transport of metallic ions. We developed a numerical ionospheric model coupled with the neutral winds from the GAIA (Ground-to-topside model of Atmosphere and lonosphere for Aeronomy). The fundamental structures and the day-to-day variations of the $E_{s}$ layers observed by a $\mathrm{Ca}^{+}$lidar are well-reproduced in the simulations.
\end{abstract}

Keywords: Sporadic E, lonosphere, Simulation, Neutral wind, Mid-latitude

\section{Introduction}

A sporadic $E\left(E_{s}\right)$ layer is a thin layer appearing in the lower ionosphere that consists of metallic ions such as $\mathrm{Fe}^{+}, \mathrm{Mg}^{+}$and $\mathrm{Ca}^{+}$. Es layers have been studied extensively since the middle of the twentieth century because they cause anomalous propagation of radio waves utilized for communication and broadcast (e.g., Whitehead 1970). More recently, it became known that the $E_{s}$ layers have a potential impact on air-navigation applications using very high frequency waves (Sakai et al. 2019).

It is widely accepted that the vertical shears of the horizontal winds of the diurnal/semi-diurnal atmospheric tides, which are dominant in the lower ionosphere, are responsible for the formation of the $E_{s}$ layers (Whitehead 1961; Axford 1963). In consideration of this, the $E_{s}$ layers are also called the tidal ion layers (Mathews 1998). According to the meridional wind-shear mechanism, the

\footnotetext{
*Correspondence: andoh@kugi.kyoto-u.ac.jp

${ }^{1}$ Graduate School of Science, Kyoto University, Kyoto, Japan

Full list of author information is available at the end of the article
}

wind shears characterized northward winds above and southward winds below (for the northern hemisphere) accumulate ions to wind-shear nulls through the ionneutral collisions and ion motions along the magnetic field lines. According to the zonal wind-shear mechanism, the wind shears characterized westward winds above and eastward winds below accumulate ions to wind-shear nulls through the ion-neutral collisions and the Lorentz force exerted by the northward geomagnetic field. It is generally considered that not the meridional wind but the zonal wind shears cause the formation of $E_{s}$ layers especially below $120 \mathrm{~km}$ altitude (e.g., Haldoupis 2011). An $E_{s}$ layer is formed at the null and descends with the downward phase propagation of the tides. The typical descent velocity of the layer formed by the semi-diurnal tide is $0.6-3 \mathrm{~m} / \mathrm{s}$ (Whitehead 1989).

Several simulations have been performed to investigate the tidal effects in $E_{s}$ layers (Carter and Forbes 1999; Krall et al. 2020; Mathews and Bekeny 1979). However, the neutral winds used in these simulations did not consider the day-to-day variability of the tides and thus, the $E_{s}$ layers were neither quantitatively nor qualitatively reproduced. Recently, a self-consistent, whole atmosphere-ionosphere model GAIA (Ground-to-topside 
model of Atmosphere and Ionosphere for Aeronomy) has reproduced 3-D thermospheric neutral winds exhibiting the day-to-day variability of realistic atmospheric tides by nudging the meteorological reanalysis data at the lower atmosphere (Jin et al. 2012). Shinagawa et al. (2017) estimated the occurrence rate of $E_{s}$ layers from ion convergences derived from the horizontal neutral winds of GAIA and compared it with the occurrence rate of $E_{s}$ layers deduced from GPS-CHAMP radio occultation (Shinagawa et al. 2017). The estimated occurrence rate of $E_{s}$ layers in general agrees with the seasonal and geographical variation of the observed rate. However, the timealtitude structures of the $E_{S}$ layers and their day-to-day variability have not been investigated because the exact transport process of metal ions has not been included in GAIA.

In the present study, we developed a 3-D numerical local ionospheric model for the metal ion layer with the neutral winds of GAIA. We simulate the fundamental structures and the day-to-day variations of $E_{S}$ layers, and then compare the variations with lidar observations performed at Tokyo.

\section{Model description}

We developed a 3-D numerical regional model of the ionospheric $E$ region and the lower $F$ region to study the three-dimensional structure of the $E_{s}$ layers. $\mathrm{Ca}^{+}$ is used in the model as a proxy for metal ions. This model focuses on metal ion transport because the metal ions are long-lived (Murad and Williams 2002) and their chemical reactions are relatively unimportant. The continuity and momentum equations of the ions are written as

$$
\begin{aligned}
\frac{\partial N_{i}}{\partial t}+ & \nabla \cdot\left(N_{i} \boldsymbol{V}_{i}\right)=P_{i}-L_{i} \\
\boldsymbol{V}_{i}= & \frac{\zeta}{1+\zeta^{2}} \frac{\boldsymbol{u} \times \boldsymbol{B}}{B}+\frac{\boldsymbol{u} \cdot \boldsymbol{B}}{1+\zeta^{2}} \frac{\boldsymbol{B}}{B^{2}}+\frac{\zeta^{2}}{1+\zeta^{2}} \boldsymbol{u} \\
& +\frac{-\frac{\nabla\left(N_{e} k_{B} T_{e}\right)}{N_{e}} \cdot \boldsymbol{B}}{m_{i} v_{i n}\left(1+\zeta^{2}\right)} \frac{\boldsymbol{B}}{B^{2}}+\frac{1}{1+\zeta^{2}} \frac{\boldsymbol{F} \times \boldsymbol{B}}{q B^{2}} \\
& +\frac{\boldsymbol{F} \cdot \boldsymbol{B}}{m_{i} v_{i n}\left(1+\zeta^{2}\right)} \frac{\boldsymbol{B}}{B^{2}}+\frac{\zeta}{1+\zeta^{2}} \frac{\boldsymbol{F}}{q B} \\
\boldsymbol{F} \equiv & -\frac{1}{N_{i}} \nabla\left(N_{i} k_{B} T_{i}\right)+m_{i} \boldsymbol{g},
\end{aligned}
$$

where $i$ represents the ion species such as $\mathrm{NO}^{+}, \mathrm{O}_{2}^{+}$, $\mathrm{O}^{+}$, or $\mathrm{Ca}^{+}$, and $e$ represents electrons. $N$ is the number density, $V$ the velocity, $P$ and $L$ the chemical produc-

\begin{tabular}{|c|c|c|}
\hline Reaction & Rate coefficient $\left[\mathrm{m}^{3} \cdot \mathrm{s}^{-1}\right]$ & References \\
\hline $\mathrm{O}^{+}+\mathrm{O}_{2} \rightarrow \mathrm{O}_{2}^{+}+\mathrm{O}$ & $k_{1}=2.1 \times 10^{-17}$ & $\begin{array}{l}\text { Schunk and Nagy } \\
\text { (2009) }\end{array}$ \\
\hline $\mathrm{O}^{+}+\mathrm{NO} \rightarrow \mathrm{NO}^{+}+\mathrm{O}$ & $k_{2}=8.0 \times 10^{-19}$ & $\begin{array}{l}\text { Schunk and Nagy } \\
\text { (2009) }\end{array}$ \\
\hline $\mathrm{O}^{+}+\mathrm{N}_{2} \rightarrow \mathrm{NO}^{+}+\mathrm{N}$ & $k_{3}=1.2 \times 10^{-18}$ & $\begin{array}{l}\text { Schunk and Nagy } \\
\text { (2009) }\end{array}$ \\
\hline $\mathrm{O}_{2}^{+}+\mathrm{NO} \rightarrow \mathrm{NO}^{+}+\mathrm{O}_{2}$ & $k_{4}=4.6 \times 10^{-16}$ & $\begin{array}{l}\text { Schunk and Nagy } \\
\text { (2009) }\end{array}$ \\
\hline $\mathrm{O}_{2}^{+}+\mathrm{N} \rightarrow \mathrm{NO}^{+}+\mathrm{O}$ & $k_{5}=1.5 \times 10^{-16}$ & $\begin{array}{l}\text { Schunk and Nagy } \\
\text { (2009) }\end{array}$ \\
\hline $\mathrm{O}_{2}^{+}+\mathrm{N}_{2} \rightarrow \mathrm{NO}^{+}+\mathrm{NO}$ & $k_{6}=1.0 \times 10^{-21}$ & Ferguson (1973) \\
\hline $\mathrm{N}^{+}+\mathrm{O}_{2} \rightarrow \mathrm{O}_{2}^{+}+\mathrm{N}$ & $k_{7}=3.07 \times 10^{-16}$ & $\begin{array}{l}\text { Schunk and Nagy } \\
\text { (2009) }\end{array}$ \\
\hline $\mathrm{N}^{+}+\mathrm{O}_{2} \rightarrow \mathrm{NO}^{+}+\mathrm{O}$ & $k_{8}=2.32 \times 10^{-16}$ & $\begin{array}{l}\text { Schunk and Nagy } \\
\text { (2009) }\end{array}$ \\
\hline $\mathrm{N}^{+}+\mathrm{O} \rightarrow \mathrm{O}^{+}+\mathrm{N}$ & $k_{9}=1.0 \times 10^{-18}$ & Joel (1985) \\
\hline $\mathrm{N}_{2}^{+}+\mathrm{O} \rightarrow \mathrm{NO}^{+}+\mathrm{O}$ & $k_{10}=1.3 \times 10^{-16}$ & $\begin{array}{l}\text { Schunk and Nagy } \\
\text { (2009) }\end{array}$ \\
\hline $\mathrm{N}_{2}^{+}+\mathrm{O}_{2} \rightarrow \mathrm{O}_{2}^{+}+\mathrm{N}_{2}$ & $k_{11}=5.0 \times 10^{-17}$ & $\begin{array}{l}\text { Schunk and Nagy } \\
\text { (2009) }\end{array}$ \\
\hline $\mathrm{N}_{2}^{+}+\mathrm{NO} \rightarrow \mathrm{NO}^{+}+\mathrm{N}_{2}$ & $k_{12}=3.6 \times 10^{-16}$ & $\begin{array}{l}\text { Schunk and Nagy } \\
\text { (2009) }\end{array}$ \\
\hline $\mathrm{O}^{+}+e^{-} \rightarrow \mathrm{O}+h v$ & $k_{13}=3.7 \times 10^{-18}\left(\frac{T_{e}}{250}\right)^{-0.7}$ & $\begin{array}{l}\text { Schunk and Nagy } \\
\text { (2009) }\end{array}$ \\
\hline $\mathrm{O}_{2}^{+}+e^{-} \rightarrow \mathrm{O}+\mathrm{O}$ & $k_{14}=2.4 \times 10^{-13}\left(\frac{T_{e}}{300}\right)^{-0.7}$ & $\begin{array}{l}\text { Schunk and Nagy } \\
\text { (2009) }\end{array}$ \\
\hline$N^{+}+e^{-} \rightarrow N+h v$ & $k_{15}=3.6 \times 10^{-18}\left(\frac{T_{e}}{250}\right)^{-0.7}$ & $\begin{array}{l}\text { Schunk and Nagy } \\
\text { (2009) }\end{array}$ \\
\hline $\mathrm{N}_{2}^{+}+e^{-} \rightarrow \mathrm{N}+\mathrm{N}$ & $k_{16}=2.2 \times 10^{-13}\left(\frac{T_{e}}{300}\right)^{-0.4}$ & $\begin{array}{l}\text { Schunk and Nagy } \\
\text { (2009) }\end{array}$ \\
\hline $\mathrm{NO}^{+}+e^{-} \rightarrow \mathrm{N}+\mathrm{O}$ & $k_{17}=4.0 \times 10^{-13}\left(\frac{T_{e}}{300}\right)^{-0.5}$ & $\begin{array}{l}\text { Schunk and Nagy } \\
\text { (2009) }\end{array}$ \\
\hline $\mathrm{O}+h v \rightarrow \mathrm{O}^{+}+e^{-}$ & EUVAC model & $\begin{array}{l}\text { Richards et al. } \\
\text { (1994) }\end{array}$ \\
\hline $\mathrm{O}_{2}+h v \rightarrow \mathrm{O}_{2}^{+}+e^{-}$ & EUVAC model & $\begin{array}{l}\text { Richards et al. } \\
\text { (1994) }\end{array}$ \\
\hline$N+h v \rightarrow N^{+}+e^{-}$ & EUVAC model & $\begin{array}{l}\text { Richards et al. } \\
\text { (1994) }\end{array}$ \\
\hline$N_{2}+h v \rightarrow N_{2}^{+}+e^{-}$ & EUVAC model & $\begin{array}{l}\text { Richards et al. } \\
\text { (1994) }\end{array}$ \\
\hline
\end{tabular}
tion and loss, respectively, $q$ the elementary charge, $B$ the geomagnetic field, $\boldsymbol{g}$ the gravitational acceleration,
Table 1 Chemical and photochemical reactions of $\mathrm{NO}^{+}$, $\mathrm{O}_{2}^{+}, \mathrm{O}^{+}, \mathrm{N}_{2}^{+}, \mathrm{N}^{+}$

$k_{B}$ the Boltzmann constant, $m$ the mass, $T$ the temperature, $v_{i n}$ the ion collision frequency with neutrals, and $\boldsymbol{U}$ the velocity of neutrals. $\zeta$ is the ratio of the ion collision frequency with neutrals to the ion gyrofrequency. $v_{i n}$ is obtained from Schunk and Nagy (2009). The chemical reactions in the model are shown in Tables 1 and 2 . Table 1 presents the chemical and photo chemical reactions of non-metal ions, and Table 2 those of $\mathrm{Ca}^{+} . \mathrm{N}^{+}$ and $\mathrm{N}_{2}^{+}$are included only in the chemical processes. $T_{n}=T_{i}=T_{e}$ is assumed in the model. A loss term due to three-body reactions involving $\mathrm{Ca}^{+}$is included below 
Table 2 Chemical and photochemical reaction of $\mathrm{Ca}^{+}$

\begin{tabular}{lll}
\hline Reaction & ${ }^{1}$ Rate coefficient & References \\
\hline $\mathrm{O}_{2}^{+}+\mathrm{Ca} \rightarrow \mathrm{Ca}^{+}+\mathrm{O}_{2}$ & $k_{18}=1.8 \times 10^{-15}$ & Rutherford et al. (1972) \\
$\mathrm{NO}^{+}+\mathrm{Ca} \rightarrow \mathrm{Ca}^{+}+\mathrm{NO}$ & $k_{19}=4.6 \times 10^{-15}$ & Rutherford et al. (1972) \\
$\mathrm{Ca}^{+}+e^{-} \rightarrow \mathrm{Ca}+h v$ & $k_{20}=3.8 \times 10^{-18}\left(\frac{T_{e}}{200}\right)^{-0.9}$ & Shull and van Steenberg (1982) \\
$\mathrm{Ca}+h v \rightarrow \mathrm{Ca}^{+}+e^{-}$ & $2 \mathrm{k}_{21}=5.0 \times 10^{-5}$ & Plane et al. (2018) \\
\hline
\end{tabular}

${ }^{1}$ Units: unimolecular, $\mathrm{s}^{-1}$; bimolecular, $\mathrm{cm}^{3}$ molecule ${ }^{-1} \mathrm{~s}^{-1}$

${ }^{2} k_{21}$ is set to 0 if the solar zenith angle is greater than $90^{\circ}$

$100 \mathrm{~km}$ altitude in the continuity equation. The term increases with decreasing altitude and is given by $L=-$ $(z-100) \times 10^{-5} \mathrm{~s}^{-1} \mathrm{~m}^{-3}$, where $\mathrm{z} \leq 100 \mathrm{~km}$. The influence of the neutral atmosphere on the formation of $E_{s}$ layers is investigated in this study. The external electric field is not included in this model because the formation of $E_{s}$ layers is mainly caused by neutral wind-shears (Whitehead 1961; Axford 1963).

The numerical model is based on spherical coordinates. The positive directions are taken as vertically upward, southward, and eastward. The altitudinal coverage is from $85 \mathrm{~km}$ to $220 \mathrm{~km}$. The grid spacing is set to the highest resolution of $0.5 \mathrm{~km}$ between $85 \mathrm{~km}$ and 140 $\mathrm{km}$. Above $140 \mathrm{~km}$, it gradually increases from $0.5 \mathrm{~km}$ to $2 \mathrm{~km}$. The longitudinal and latitudinal domain size is $20^{\circ} \times 20^{\circ}$ with a grid spacing of $0.25^{\circ}$, and the center of the domain is located at $35.7^{\circ} \mathrm{N}$ and $139.8^{\circ} \mathrm{E}$ where the lidar observations were performed. The boundary conditions are set to zero gradients for all variables; however, at the top boundary, the densities of the ions except for $\mathrm{O}^{+}$are assumed to be in diffusive equilibrium. The number densities of neutrals except $\mathrm{Ca}$ and the neutral temperature are constrained by the NRLMSISE-00 model (Picone et al. 2002), and the geomagnetic field is taken from the IGRF-12 model (Thébault et al. 2015). The Ap and F10.7 index data are obtained from the World Data Center for Geomagnetism in Kyoto and NOAA/NCEI, respectively. The initial values of $\mathrm{Ca}$ and $\mathrm{Ca}^{+}$in the simulations are set to the annual mean profiles obtained by Plane et al. (2018), and the profiles are uniformly distributed in the horizontal domain. In order to precisely simulate ion transport, the Constrained Interpolation Profile scheme is used for the advection term (Yabe et al. 1991). The time step for solving equation (1) is $1 \mathrm{~s}$. Prior to simulations, the chemical processes were calculated for $4800 \mathrm{~s}$ to obtain the chemical equilibrium state of each ion species. Then, the presented simulations were run for $36 \mathrm{~h}$ and the first $12 \mathrm{~h}$ were discarded to remove initial transients.

In the simulations in this study, the neutral wind velocity was obtained from GAIA. The horizontal resolution of the neutral atmospheric part of GAIA is T42 (the maximum horizontal wave number is equal to 42 ), corresponding to a grid spacing of $2.8^{\circ}$ longitude by $2.8^{\circ}$ latitude, and the vertical resolution is 0.4 scale height above the tropopause (e.g., Fujiwara and Miyoshi 2010; Miyoshi and Fujiwara 2008). The neutral wind velocity of GAIA was linear-interpolated in the vertical direction and spline-interpolated in the horizontal direction when it was used as an input for the regional ionospheric model. The diurnal and the semi-diurnal tides, which were extracted from the averaged 3-D neutral winds of GAIA in June, 2015 through a Fourier decomposition, were used as inputs for Case A to reproduce the fundamental structures of the $E_{s}$ layers due to the atmospheric tides. The F10.7 and AP index are set to averaged value in June, 2015. For Case B, the 3-D neutral winds at days corresponding to the lidar observations were used as inputs for comparison with the observed temporal $\mathrm{Ca}^{+}$profile variation. The F10.7 and AP indices are set to the values on each observation day. The lidar observations were performed at the National Institute of Polar Research, Tachikawa (Ejiri et al. 2019a, b). The time and altitude resolution of the observations were reduced to $600 \mathrm{~s}$ and $0.5 \mathrm{~km}$, respectively, to match the output interval and altitude resolution of the model. The lidar observations have been operated only on eight nights in 2014-2016 because the lidar was on a development stage and not able to perform continuous observations. After the development, the lidar has been brought to the Antarctic. We were able to simulate $E_{s}$ layers only on six out of the eight nights because GAIA data are lacking for two out of eight nights. Hence, the results on the six nights shown in the next section are all of the cases we simulated.

\section{Results}

Figure 1 presents the temporal variations for Case A in which the monthly averaged tidal winds were used as inputs. The vertical axis represents the altitude from $85 \mathrm{~km}$ to $150 \mathrm{~km}$, and horizontal axis the local time for 24 hours beginning from morning. The simulated $\mathrm{Ca}^{+}$ density is shown in Fig. 1a, and the zonal, meridional 

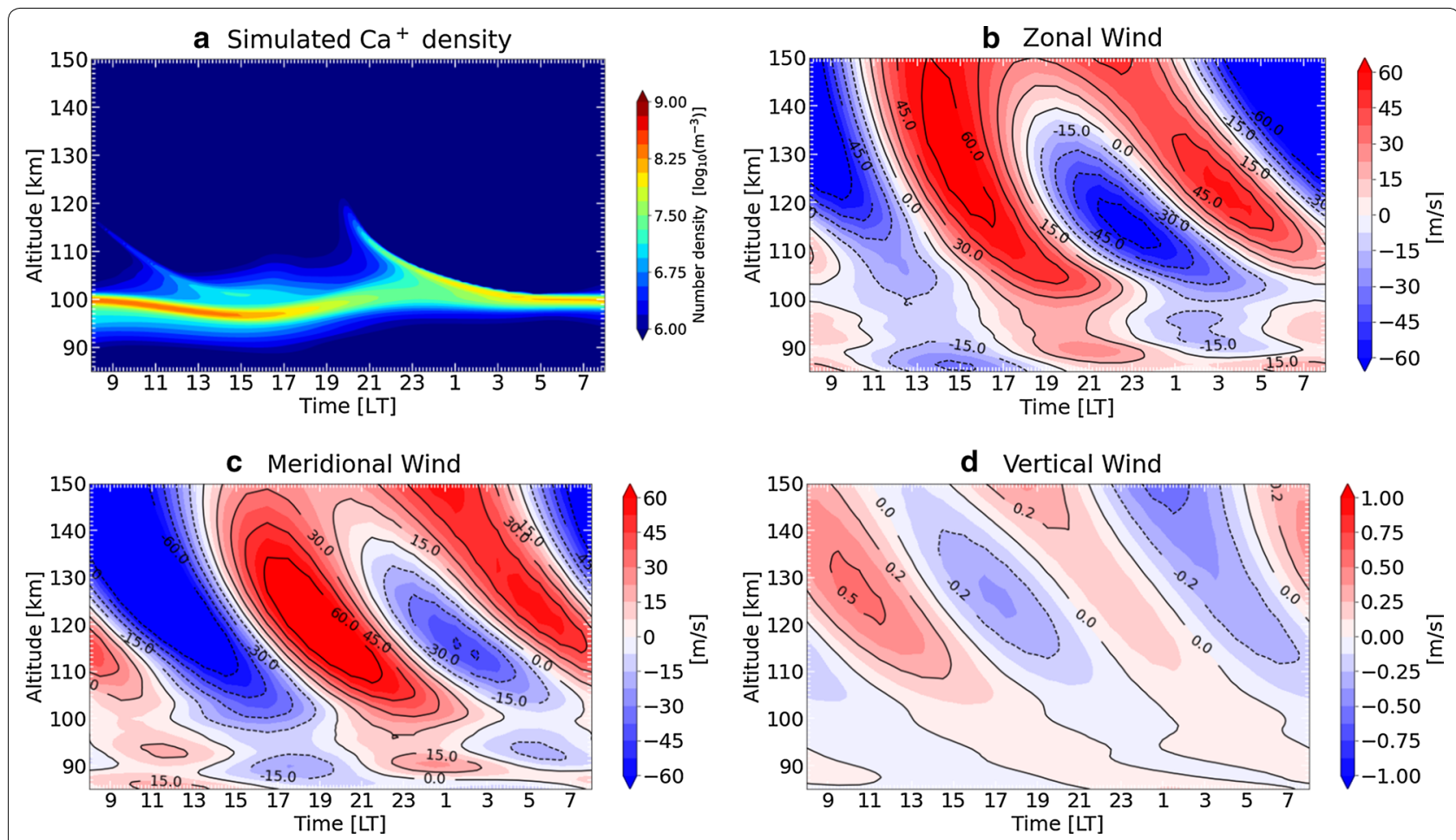

Fig. 1 Temporal variations of (a) simulated $\mathrm{Ca}^{+}$density and (b) zonal (c) meridional and (d) vertical component of neutral winds used as an input. Positive values in Fig. 1b-d represent eastward, southward and upward, respectively. "Layer 1" occurs at daytime and "Layer 2" occurs at nighttime

and vertical component of the neutral winds utilized as the inputs are shown in Fig. 1b-d, respectively. Positive values in Fig. 1b-d represent eastward, southward and upward, respectively. Two $E_{s}$ layers are seen in Fig. 1a; "Layer 1" occurs in the daytime and "Layer 2" occurs in the nighttime. The $E_{s}$ layers appear at zonal wind-shear nulls rather than meridional-wind or vertical-wind ones between 115 and $120 \mathrm{~km}$ at 8 and 20 LT. As shown in Fig. $1 \mathrm{~b}$, the semi-diurnal tide is dominant between 115 and $120 \mathrm{~km}$ where Layer 1 and Layer 2 appear, and the descending layers are produced mainly due to zonal wind shears of the semi-diurnal tide. The descending velocity of the layers becomes smaller than that of tidal phase propagation due to the increase in the ratio of the ion collision frequency with neutrals to the ion gyrofrequency as the layers descend. Therefore, the $E_{s}$ layers gradually remain behind the wind shears. Subsequently, the $E_{s}$ layers stay around $100 \mathrm{~km}$, and the descending layers merge with the stagnated layer. As a result, most of the $\mathrm{Ca}^{+}$accumulates around $100 \mathrm{~km}$ as shown in Fig. 1a. This numerical result is similar to previous $E_{s}$ layer simulation results (Carter and Forbes 1999; Krall et al. 2020; Mathews and Bekeny 1979).

In Case $\mathrm{A}$, the fundamental structure of the $E_{s}$ layer is reproduced; the $E_{s}$ layers are created by the semidiurnal tide, descend with its vertical wind shears, and remain around $100 \mathrm{~km}$. In the observations, however, the $E_{s}$ layers have more complicated structures and show large day-to-day variabilities (e.g., Ejiri et al. 2019a, b; Raizada et al. 2020). The daily neutral winds of GAIA were used as inputs in Case B to reproduce and investigate the day-to-day variability of the $E_{s}$ layer structures. The simulated temporal variations of the $\mathrm{Ca}^{+}$altitude profiles are compared with those observed by a resonant scattering lidar on six nights from 2014 to 2016 . Figure 2 presents a comparison between the temporal variations of the $\mathrm{Ca}^{+}$profiles in the simulations and the lidar observations. The left column shows the simulation results and the right column shows the lidar observations on six nights: December 8, 2015 (a and b), December 18, 2015 (c and d), August 31, 2016 (e and f), December 24, 2014 ( $g$ and h), August 21, 2014 (i and j), and September 1,2016 ( $\mathrm{k}$ and $\mathrm{l}$ ). All the lidar observation nights that have corresponding GAIA output are shown in Fig. 2. The vertical axis represents the altitude from $85 \mathrm{~km}$ to $150 \mathrm{~km}$ and the horizontal axis the local time. Note that the ranges of time in Fig. 2 are different for each night. The arrows in the panels represent the descent velocities of the $E_{s}$ layers. The subfigures are presented in order according to the number of $E_{s}$ layers in the simulation. Both Layer 1 and Layer 2 are produced by 
(See figure on next page.)

Fig. 2 Comparison between the temporal variations of the $\mathrm{Ca}^{+}$profiles of the simulated results and the lidar observations with a height/time resolution of $0.5 \mathrm{~km} / 600 \mathrm{~s}$. The left column shows the simulated results and the right column the lidar observations for 6 nights: December 8,2015 (a and b), December 18, 2015 (c and d), August 31, 2016 (e and f), December 24, 2014 (g and h), August 21, 2014 (i and j), and September 1, 2016 (k and I)

the tides, and descend to $\geq 100 \mathrm{~km}$ with the downward propagation of the tidal phase. There are several differences in

- The number of layers

- The altitudes at which the layers appear

- The decay of the layers

between the fundamental $E_{s}$ structures seen in Case A, and the day-to-day variability of the $E_{s}$ layers.

In general, the simulation successfully reproduced the observations. In Fig. $2 a$ and b, Layer 2 appears at higher altitudes and decays away after 4 LT. Layer 1 remains at the same altitude and disappears around 0 LT. On the other hand, two $E_{s}$ layers appear at $100 \mathrm{~km}$ and $110 \mathrm{~km}$ in Fig. 2c and d. The lower layer descends slightly and cannot be clearly seen after 4 LT. The altitudes at which Layer 1 and Layer 2 appear in Fig. 2e and $f$ are similar to those of the layers shown in Fig. 2c and $\mathrm{d}$, but the layers have no clear boundary between them and merge with each other at around $100 \mathrm{~km}$. Only a single layer is created by the tides in each of Fig. 2g-l. The lifetimes of the layers also seem to be well-reproduced in Fig. 2g-l. As shown in Fig. 2f, h, and $j$, additional layers appear between 110 and $120 \mathrm{~km}$ in the morning. These layers do not appear in the simulations for the corresponding days, but a similar layer is reproduced at $110 \mathrm{~km}$ and 4-6 LT in Fig. 2a. The additional layer in Fig. 2l, which appears above $110 \mathrm{~km}$ and descends at a faster velocity than the downward phase propagation of the semi-diurnal tides, is also not reproduced in the simulation.

\section{Discussion and conclusions}

We have developed a regional ionospheric model of the metal ion layer to reproduce the day-to-day variability of $E_{s}$ layers. The regional model reproduced the day-to-day variation of the $E_{s}$ layers observed by the $\mathrm{Ca}^{+}$lidar well. In Case $A$ in which the monthly averaged tidal winds were used as inputs, $E_{s}$ layers appear at $\sim 115 \mathrm{~km}$ altitude and descend to lower altitudes twice a day. The layers finally remain at $\sim 100 \mathrm{~km}$ altitude because the ions collide with neutrals more frequently below $100 \mathrm{~km}$, resulting in the ion vertical velocity becoming almost equal to the slow vertical neutral wind velocity $(\leq 0.1 \mathrm{~m} / \mathrm{s})$ in Case A. In contrast, in Case B where the daily neutral winds from GAIA were used as inputs, the $E_{s}$ layers on each night have different numbers, altitudes of appearance, and layer decay from the structures in Case A. In most of the nights shown in Fig. 2, Layer 2 appears and persists through the night. However, Layer 2 does not appear and Layer 1 persists till the morning in one out of the six nights as shown in Fig. $2 \mathrm{~g}$ and $\mathrm{h}$. The altitudes at which $E_{s}$ layers appear in Case B vary from $110 \mathrm{~km}$ to $130 \mathrm{~km}$ in the simulations and from $85 \mathrm{~km}$ to $140 \mathrm{~km}$ in the observations. It was found that the number of $E_{s}$ layers and the altitudes that they appear at depend on the strength and altitude of vertical zonal wind shears rather than the distribution of $\mathrm{Ca}^{+}$in the simulations. The dayto-day variability of the tides, which produces the variability of the vertical wind shears, is believed to be due to interaction between the tides and the planetary waves (Forbes et al. 2008; Liu et al. 2014; Miyoshi and Fujiwara 2003). The daily variation of the $E_{s}$ layer structures can be regarded as a manifestation of the day-to-day variability of the tides.

The $E_{s}$ layers that descend to $\leq 100 \mathrm{~km}$ disappear mainly because of the three-body reaction of $\mathrm{Ca}^{+}$. Whether or not the $E_{s}$ layers can descend to $\leq 100 \mathrm{~km}$ depends on the strength of the vertical neutral winds around $100 \mathrm{~km}$ altitude. Figure 3 shows the temporal variations of (a) vertical ion velocity, (b) zonal winds, (c) meridional winds and (d) vertical winds on December 18, 2015 , where the $E_{s}$ layer descends clearly to $<100 \mathrm{~km}$. The horizontal axis is same as Fig. 2c, but the range of altitude is from $85 \mathrm{~km}$ to $130 \mathrm{~km}$ altitude because the $E_{s}$ layers in Fig. 2c appear below $130 \mathrm{~km}$ and the vertical ion velocity above $130 \mathrm{~km}$ is mostly controlled by the meridional winds that is same as the previous numerical results (Carter and Forbes 1999; Krall et al. 2020). Positive values in Fig. 3a-d represent upward, eastward, southward and upward, respectively. The temporal variation of vertical ion velocity at $100-130 \mathrm{~km}$ has similar feature to that of zonal winds. In contrast, the feature of the temporal variation of vertical ion velocity below $100 \mathrm{~km}$ resembles that of vertical winds and not meridional winds. The vertical ion velocity below $100 \mathrm{~km}$, which is equal to the vertical neutral wind velocity there, reaches up to $\sim 0.5 \mathrm{~m} / \mathrm{s}$ in Case $\mathrm{B}$ and is larger than that in Case $\mathrm{A}$. When the vertical neutral wind velocity is nearly $0.5 \mathrm{~m} / \mathrm{s}$, the layers in Case B descend to $\leq 100 \mathrm{~km}$ altitude and become neutralized by the three-body reaction of $\mathrm{Ca}^{+}$. The simulated 

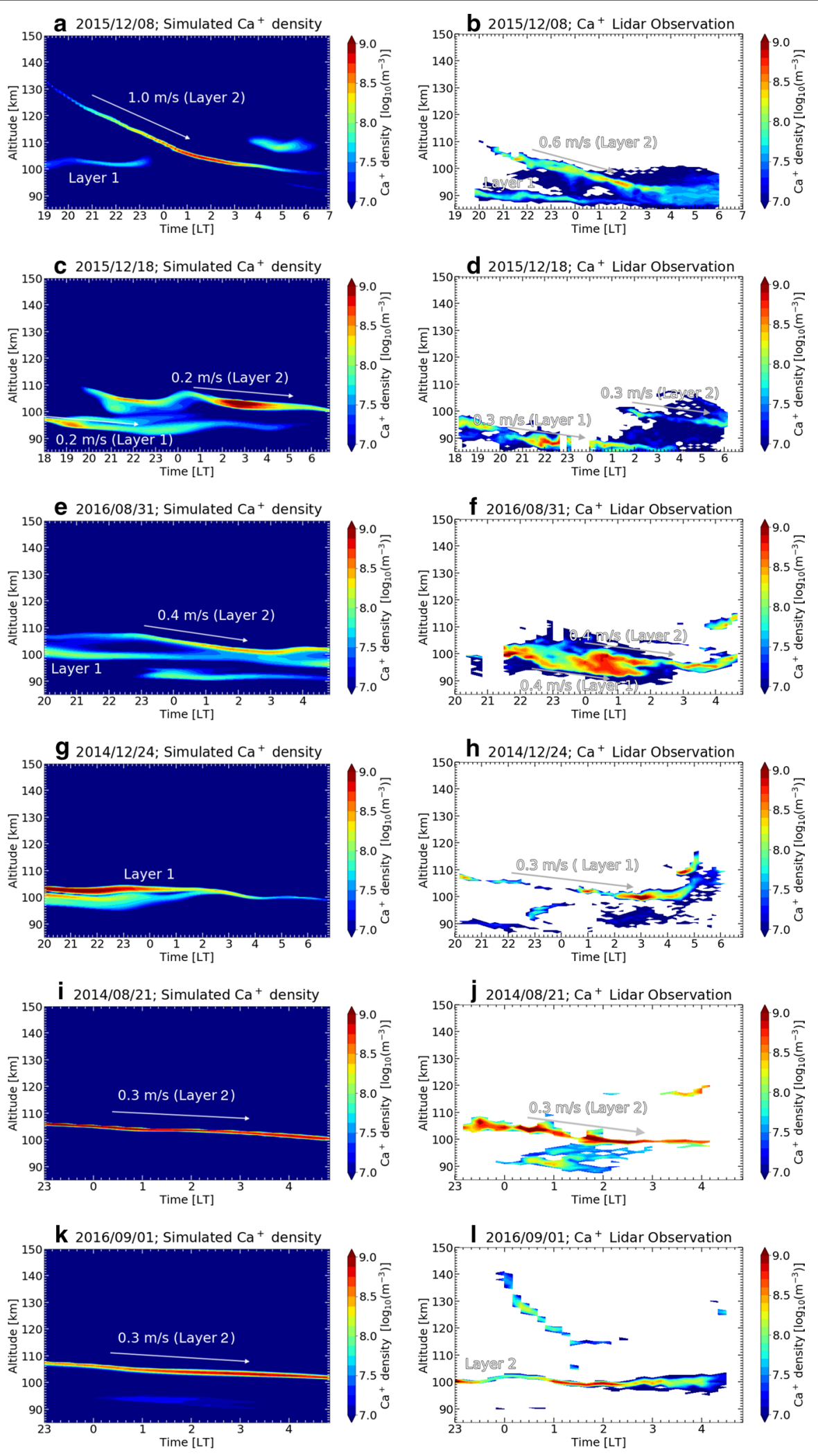


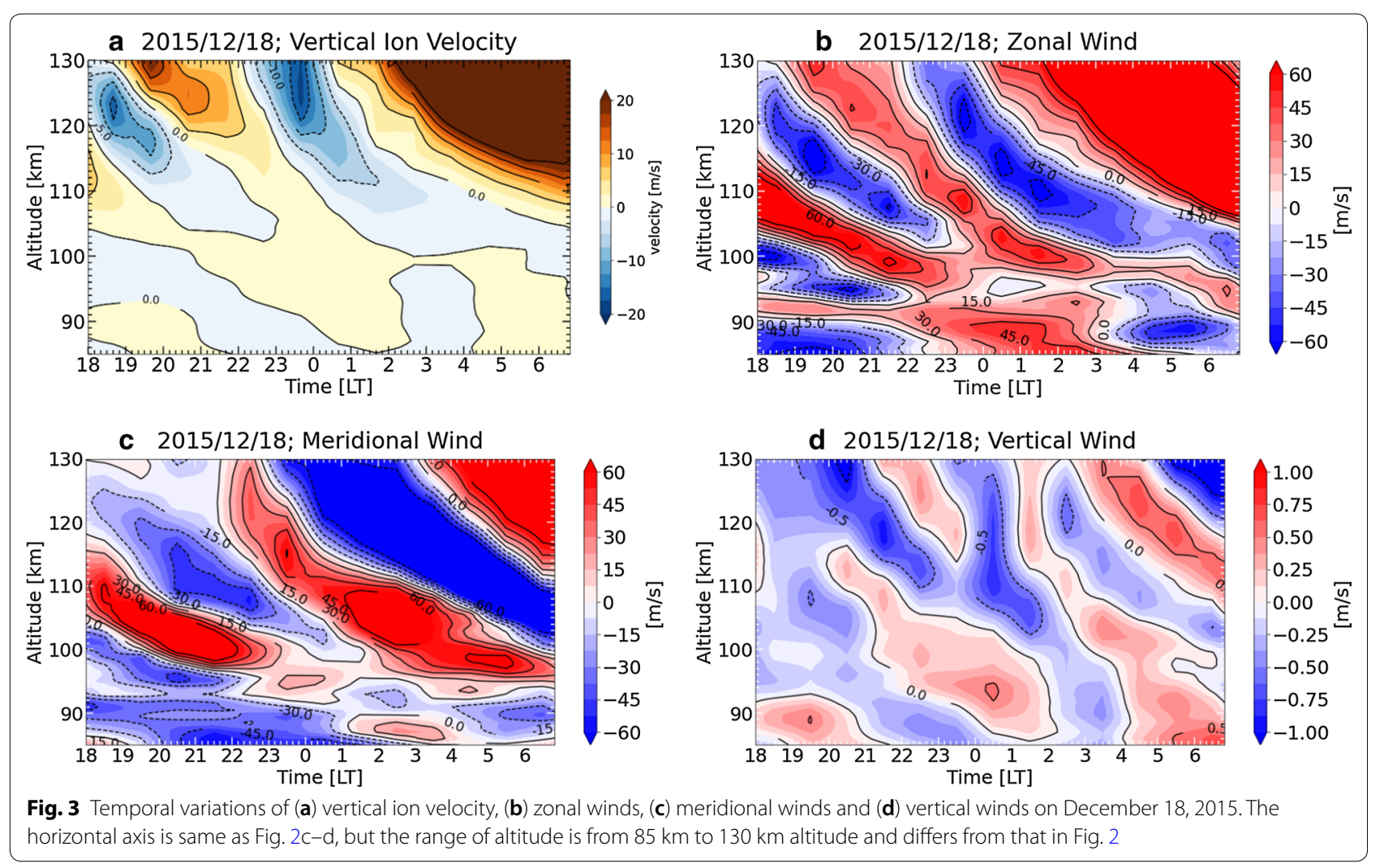

Layer 1 shown in Fig. 2a, c, and e appears at a slightly higher altitude than the observed Layer 1 . This indicates that the strength of the actual downward neutral winds might be stronger than that in the simulations. Previous numerical studies have neglected the influence of vertical neutral winds on $E_{S}$ layers (Carter and Forbes 1999; Krall et al. 2020; Mathews and Bekeny 1979), but many $E_{s}$ layers have been observed below $100 \mathrm{~km}$ (Ejiri et al. 2019a, b; Raizada et al. 2011, 2020). Krall et al. (2020) have suggested that meridional winds account for the $E_{s}$ layers below $110 \mathrm{~km}$ because the SAMI3 simulations in "meridional winds only" case have reproduced observed layers below $110 \mathrm{~km}$ and the simulated layers have been associated with wind shears of meridional winds. As shown in Fig. 3, however, vertical ion motions below $110 \mathrm{~km}$ mostly result from zonal or vertical winds not from meridional winds. The $E_{s}$ layers below $110 \mathrm{~km}$ are not completely restricted by the wind shears (e.g., Haldoupis 2012). Therefore, $E_{s}$ layer structures might be influenced by horizontal transport by horizontal neutral winds rather than ion vertical convergence by the winds. Thus, it is crucial that the vertical neutral wind effects on $E_{s}$ layer structures below $100 \mathrm{~km}$ are included in simulations and the 3-D dynamics of simulated layers are investigated.
In addition to Layer 1 and Layer 2, other layers are seen in Fig. 2. They are morning $E_{s}$ layers that appear around $110-120 \mathrm{~km}$ and 3-5 LT as shown in Fig. $2 \mathrm{f}, \mathrm{h}$ and $\mathrm{j}$, and an $E_{s}$ layer that descends between 120 and $140 \mathrm{~km}$ with greater velocity than the phase velocity of the semi-diurnal tides shown in Fig. 2l. These discrepancies are induced because the neutral winds of GAIA do not contain all the atmospheric waves that cause $E_{s}$ layers because of the low spatial resolution. Figure $2 \mathrm{a}$ shows that the morning $E_{s}$ layer is reproduced in the simulation, but it is not observed as shown in Fig. 2b. In contrast, the observed morning $E_{s}$ layers in Fig. $2 \mathrm{f}, \mathrm{h}$ and $\mathrm{j}$ are not reproduced. The simulated morning layer is a part of the 3-D structure of $E_{s}$ layers that moves horizontally. The 3-D structures of $E_{s}$ layers and their dynamics may play important roles in the complexity of the observed $E_{s}$ layers such as the morning layers and the fast descending layer. Further simulations are necessary to elucidate the effects of the atmospheric tides and, especially, the atmospheric gravity waves on the 3-D $E_{s}$ structures in terms of ionosphere-thermosphere coupling. In the present study, we emphasize the effect of the neutral winds on the $E_{s}$ layers because it is known for the neutral winds to affect the fundamental structures of the $E_{s}$ layers (e.g., Whitehead 1989; Mathews 1998; Haldoupis 2012), and the effect of the polarization electric fields on the $E_{s}$ layers is beyond 
our scope. The polarization electric field may be crucial for the small-scale structures of the $E_{s}$ layers especially in the nighttime (e.g., Cosgrove and Tsunoda 2003; Yokoyama et al. 2009) and influence the day-to-day variation of the layers; this will be addressed in future studies. Statistical analysis of the simulated results is needed to reveal the mechanisms of long-standing problems such as the seasonal and local time dependence of $E_{s}$ layer occurrence (e.g., Whitehead 1989). We believe that the combination of the 3-D metallic ion model and the GAIA model will improve our knowledge of the 3-D structures of $E_{s}$ layers and their formation mechanisms.

\section{Abbreviations \\ GAIA:: Ground-to-topside model of Atmosphere and lonosphere for Aer- onomy; Sporadic $E:: E_{s}$.}

\section{Acknowledgements}

We express our deep thanks to Dr. S. Miyazaki, associate professor, Graduate School of Science, Kyoto University, for his help and support to attain this research. This lidar development and observations were supported by the JSPS-KAKENHI (JP15K13575), the prioritized project AJ1 and AJ0901 of Japanese Antarctic Research Expedition, the Project Research KP2 and KP301 of the National Institute of Polar Research, and RIKEN-RAP. This work was also supported by JSPS-KAKENHI (JP15H05815). The Ap index data were provided by the Data Analysis Center for Geomagnetism and Space Magnetism, Kyoto University (http://wdc.kugi.kyoto-u.ac.jp/wdc/Sec3.html). The F10.7 index data were obtained from NOAA/NCEl (https://www.ngdc.noaa.gov/stp/space weather.html). Raw data of GAIA are available at https://gaia-web.nict.go.jp/ data_e.html. The $\mathrm{Ca}^{+}$density data observed by a lidar are available in the data repository at http://id.nii.ac.jp/1291/00015894/. The simulated Ca+ density data are available at https://doi.org/10.14989/250701. Numerical information associated with Fig. 1b-d can be downloaded at https://doi.org/10.14989 /250701.

\section{Authors' contributions}

SA developed the ionospheric numerical model for metal ion layer and conducted the simulations, and wrote the paper. AS discussed the results and contributed to revise the paper. HS conceived and designed the study. MKE performed the lidar observation. All authors read and approved the final manuscript.

\section{Funding}

Fundings were provided by JSPS-KAKENHI (JP15K13575) and JSPS-KAKENHI (JP15H05815).

\section{Availability of data and materials}

Raw data of GAIA is available at https://gaia-web.nict.go.jp/data_e.html. The $\mathrm{Ca}^{+}$density data observed by a lidar are available in the data repository at http://id.nii.ac.jp/1291/00015894/. The simulated Ca+ density data are available at https://doi.org/10.14989/250701. Numerical information associated with Fig. 1b-d can be downloaded at https://doi.org/10.14989/250701. Additional data products referred to in this paper are available from the corresponding author.

\section{Competing interests}

The authors declare that they have no competing interests.

\section{Author details}

${ }^{1}$ Graduate School of Science, Kyoto University, Kyoto, Japan. ${ }^{2}$ National Institute of Information and Communication Technology, Tokyo, Japan. ${ }^{3}$ National Institute of Polar Research, Tokyo, Japan. ${ }^{4}$ Department of Polar Science, SOKENDAI, The Graduate University for Advanced Studies, Tokyo, Japan.
Received: 24 August 2020 Accepted: 19 October 2020

Published online: 31 October 2020

\section{References}

Axford WI (1963) The formation and vertical movement of dense ionized layers in the ionosphere due to neutral wind shears. J Geophys Res 68(3):769779. https://doi.org/10.1029/JZ068i003p00769

Carter LN, Forbes JM (1999) Global transport and localized layering of metallic ions in the upper atmosphere. Ann Geophys 17:190-209

Cosgrove RB, Tsunoda RT (2003) Simulation of the nonlinear evolution of the sporadic-E layer instability in the nighttime midlatitude ionosphere. J Geophys Res. https://doi.org/10.1029/2002JA009728

Ejiri MK, Nakamura T, Tsuda TT, Nishiyama T, Abo M, Takahashi T, Tsuno K, Kawahara TD, Ogawa T, Wada S (2019a) Vertical fine structure and time evolution of plasma irregularities in the Es layer observed by a high-resolution $\mathrm{Ca}^{+}$lidar. Earth Planets Space 71:3

Ejiri MK, Nakamura T, Tsuda TT, Nishiyama T, Abo M, She CY, Nishioka M, Saito A, Takahashi T, Tsuno K, Kawahara TD, Ogawa T, Wada S (2019b) Observation of synchronization between instabilities of the sporadic E layer and geomagnetic field line connected $\mathrm{F}$ region medium-scale traveling ionospheric disturbances. J Geophys Res 124(6):4627-4638

Ferguson EE (1973) Rate constants of thermal energy binary ionmolecule reactions of aeronomic interest. Atom Data Nucl Data Tables 12(2):159-178

Forbes JM, Zhang X, Palo S, Russell J, Mertens CJ, Mlynczak M (2008) Tidal variability in the ionospheric dynamo region. J Geophys Res. https://doi. org/10.1029/2007JA012737

Fujiwara H, Miyoshi Y (2010) Morphological features and variations of temperature in the upper thermosphere simulated by a whole atmosphere GCM. Ann Geophys 28(2):427-437. https://doi.org/10.5194/angeo-28-427-2010

Haldoupis C (2011) A Tutorial Review on Sporadic E Layers. In: Abdu MA, Pancheva D (eds) Aeronomy of the earth's atmosphere and ionosphere. Springer: Netherlands, pp 381-394, https://doi. org/10.1007/978-94-007-0326-1_29

Haldoupis C (2012) Midlatitude sporadic E. A typical paradigm of atmosphereionosphere coupling. Space Sci Rev 168(1-4):441-461. https://doi. org/10.1007/s11214-011-9786-8

Jin H, Miyoshi Y, Pancheva D, Mukhtarov P, Fujiwara H, Shinagawa H (2012) Response of migrating tides to the stratospheric sudden warming in 2009 and their effects on the ionosphere studied by a whole atmosphere-ionosphere model GAIA with COSMIC and TIMED/SABER observations. J Geophys Res 117(10):A10-323

Joel $L$ (1985) The photochemistry of atmospheres. Academic Press, Cambridge

Krall J, Huba JD, Nossa E, Aponte N, Drob DP (2020) AMI3 simulations of ionospheric metallic layers at arecibos. J Geophys Res 125(3):e2019JA027-297. https://doi.org/10.1029/2019JA027297

Liu X, Xu J, Yue J, Liu HL, Yuan W (2014) Large winds and wind shears caused by the nonlinear interactions between gravity waves and tidal backgrounds in the mesosphere and lower thermosphere. J Geophys Res 119(9):7698-7708. https://doi.org/10.1002/2014JA020221

Mathews JD (1998) Sporadic E: current views and recent progress. J Atmos Sol-Terr Phys 60(4):413-435

Mathews JD, Bekeny FS (1979) Upper atmosphere tides and the vertical motion of ionospheric sporadic layers at Arecibo. J Geophys Res 84(A6):2743-2750. https://doi.org/10.1029/JA084iA06p02743

Miyoshi Y, Fujiwara H (2003) Day-to-day variations of migrating diurnal tide simulated by a GCM from the ground surface to the exobase. Geophys Res Lett. https://doi.org/10.1029/2003GL017695

Miyoshi Y, Fujiwara H (2008) Gravity waves in the thermosphere simulated by a general circulation model. J Geophys Res. https://doi.org/10.1029/2007J D008874

Murad E, Williams I (2002) Meteors in the Earth's Atmosphere Ch. 8. Cambridge University Press, Cambridge

Picone JM, Hedin AE, Drob DP, Aikin AC (2002) NRLMSISE-00 empirical mode of the atmosphere: statistical comparisons and scientific issues. J Geophys Res 107(A12):1468

Plane JMC, Feng W, Gómez Martín JC, Gerding M, Raizada S (2018) A new model of meteoric calcium in the mesosphere and lower thermosphere. Atmos Chem Phys 18(20):14,799-14,811 
Raizada S, Tepley CA, Aponte N, Cabassa E (2011) Characteristics of neutral calcium and $\mathrm{Ca}^{+}$near the mesopause, and their relationship with sporadic ion/electron layers at Arecibo. Geophys Res Lett 38(9):L09103

Raizada S, Smith JA, Lautenbach J, Aponte N, Perillat P, Sulzer M, Mathews JD (2020) New lidar observations of $\mathrm{Ca}^{+}$in the mesosphere and lower thermosphere over arecibo. Geophys Res Lett 47(5):e2020GL087-113. https:// doi.org/10.1029/2020GL087113

Richards PG, Fennelly JA, Torr DG (1994) EUVAC: a solar EUV flux model for aeronomic calculations. J Geophys Res 99(A5):8981-8992

Rutherford JA, Mathis RF, Turner BR, Vroom DA (1972) Formation of calcium ions by charge transfer. J Chem Phys 57(8):3087-3090

Sakai J, Hosokawa K, Tomizawa I, Saito S (2019) A statistical study of anomalous VHF propagation due to the sporadic-E layer in the air-navigation band. Radio Sci 54(5):426-439

Schunk R, Nagy A (2009) Ionospheres. Cambridge University Press, Cambridge Shinagawa H, Miyoshi Y, Jin H, Fujiwara H (2017) Global distribution of neutral wind shear associated with sporadic E layers derived from GAIA. J Geophys Res 122(4):4450-4465

Shull JM, van Steenberg M (1982) The ionization equilibrium of astrophysically abundant elements. Astrophys J Suppl 48:95-107

Thébault E, Finlay CC, Beggan CD, Alken P, Aubert J, Barrois O, Bertrand F, Bondar T, Boness A, Brocco L, Canet E, Chambodut A, Chulliat A, Coïsson
P, Civet F, Du A, Fournier A, Fratter I, Gillet N, Hamilton B, Hamoudi M, Hulot G, Jager T, Korte M, Kuang W, Lalanne X, Langlais B, Léger JM, Lesur V, Lowes FJ, Macmillan S, Mandea M, Manoj C, Maus S, Olsen N, Petrov V, Ridley V, Rother M, Sabaka TJ, Saturnino D, Schachtschneider R, Sirol O, Tangborn A, Thomson A, TØffner-Clausen L, Vigneron P, Wardinski I, Zvereva T, (2015) International geomagnetic reference field: the 12th generation. Earth Planets Space 67:79

Whitehead JD (1961) The formation of the sporadic-E layer in the temperate zones. J Atmos Terr Phys 20(1):49-58

Whitehead JD (1970) Production and prediction of sporadic E. Rev Geophys Space Phys 8(1):65-144

Whitehead JD (1989) Recent work on mid-latitude and equatorial sporadic-E. J Atmos Terr Phys 51(5):401-424

Yabe T, Ishikawa T, Wang PY, Aoki T, Kadota Y, Ikeda F (1991) A universal solver for hyperbolic equations by cubic-polynomial interpolation II. Two- and three-dimensional solvers. Comput Phys Commun 66(2):233-242

Yokoyama T, Hysell DL, Otsuka Y, Yamamoto M (2009) Three-dimensional simulation of the coupled Perkins and Es-layer instabilities in the nighttime midlatitude ionosphere. J Geophys Res. https://doi.org/10.1029/2008J A013789

\section{Submit your manuscript to a SpringerOpen ${ }^{\odot}$ journal and benefit from:}

- Convenient online submission

- Rigorous peer review

- Open access: articles freely available online

- High visibility within the field

- Retaining the copyright to your article

Submit your next manuscript at $\boldsymbol{\nabla}$ springeropen.com 